\title{
Frequency and Risk Factors Association of Fall Among the Idiopathic Parkinson's Patients in Jashore, Bangladesh
}

\author{
Goutam Kumar Acherjya ${ }^{1, *}$, Mohammad Ali $^{2}$, Mostofa Kamal ${ }^{3}$, Rajashish Chakkraborty ${ }^{4}$, \\ Md Anwar Shahadat ${ }^{5}$, AV Srinivashan ${ }^{6}$ \\ ${ }^{1}$ Upazila Health Complex, Bagherpara, Jashore, Bangladesh \\ ${ }^{2}$ Department of Hematology, National Institute of Cancer Research and Hospital, Dhaka, Bangladesh \\ ${ }^{3}$ Department of Medicine, Shaheed Suhrawardy Medical College and Hospital, Dhaka, Bangladesh \\ ${ }^{4}$ Department of Respiratory Medicine, Bangabandhu Sheikh Mujib Medical University, Dhaka, Bangladesh \\ ${ }^{5}$ Zakia Wahid Hossain Medical Care, Jamaica, New York, United States of America \\ ${ }^{6}$ Institute of Neurology, Madras Medical College and Research Institute, Chennai, Tamil Nadu, India \\ Email address: \\ gacherjya@hotmail.com (G. K. Acherjya) \\ ${ }^{*}$ Corresponding author
}

\section{To cite this article:}

Goutam Kumar Acherjya, Mohammad Ali, Mostofa Kamal, Rajashish Chakkraborty, Md Anwar Shahadat, AV Srinivashan. Frequency and Risk Factors Association of Fall Among the Idiopathic Parkinson's Patients in Jashore, Bangladesh. American Journal of Internal Medicine. Vol. 7, No. 2, 2019, pp. 36-40. doi: 10.11648/j.ajim.20190702.13

Received: March 28, 2019; Accepted: March 5, 2019; Published: May 30, 2019

\begin{abstract}
Parkinson's disease is the second most common neuro degenerative disease worldwide. Fall is common scenario in our day to day clinical practice among the older people but it is more common among the Parkinson's people. The study was conducted to assess the frequency of fall and to ascertain the risk association among the idiopathic Parkinson's patients. This observational study was conducted from July to December, 2018 in the district of Jashore, Bangladesh. Both the male and female clinically diagnosed as idiopathic Parkinson's disease without taking antiparkinsonian medication were recruited in the study. Those having Parkinson's disease due to stroke or secondary causes, orthostatic hypotension, taking anti parkinsonian drugs and the drugs may mimicking Parkinson's disease were excluded from the study. A total 111 patients were analyzed of which $69.4 \%(\mathrm{~N}=77)$ male and $30.6 \%(\mathrm{~N}=34)$ female with the mean age of our participants was $66 \pm 10$ years. The event of fall among the idiopathic Parkinson's patients was $36.9 \%$ in the last one year where single, two and three or more episodes of fall were $20.7 \%, 3.6 \%$ and $12.6 \%$ respectively. No significant difference observed between faller and non-fallers among different demographic characteristics including age ( $p: 0.091)$ sex $(p: 0.058)$ educational level $(p: 0.235)$, occupational status $(p: 0.220)$ and residency ( $p: 0.547)$. Experience of fall found more in high BMI ( $p: 0.037)$, hypertensive ( $p: 0.018)$, diabetic $(p: 0.009)$ and in patients receiving multiple medications ( $p: 0.011)$. But duration of Parkinsonism ( $p: 0.835)$ does not increase fall. Based on this study, we have found that there is high frequency of fall among the idiopathic Parkinson's patients. So, earlier identification and potential strategies to remove the risk factors may prevent falls and falls related events, thus finally reducing the morbidity and mortality in the Parkinson's patients.
\end{abstract}

Keywords: Fall, Frequency, Risk Factors, Idiopathic Parkinson's Disease

\section{Introduction}

Fall is one of the crucial points in the management of Parkinson's disease (PD), with its higher impact on morbidity, mortality, hospital admission, impaired quality of life and resources. [1] Though a lot of factors are related to falls in PD, the most important factor for next falls is a history of previous falls. [2] The common predictors of falls in PD are increasing age, disease duration, disease severity, autonomic dysfunction, urinary incontinence, increase time in the Get-Up-and-Go test, greater postural sway, poorer stability in response to pushes and pulls, variability of stride time, poor balance while standing, dyskinesia, dementia, 
frontal impairment, gait freezing, orthostatic hypotension and muscle weakness. [3] Fall experienced in most of the PD patients is due to the result of disease symptoms and most of them have experiences with recurrent episodes of fall. [4] The results of frequent fall among the PD patients are directly related to high risk of fractures and it is estimated two times more risk than the healthy controls. [5] The other features that results from fall in PD patients are anxiety, reduced self-efficacy, weakness and mobility. [6] Finally, fall and fractures may result in an unfavorable condition, such as disability and death; the mortality rate is approximately $10.6 \%$. [7] Though fall is a simple word but its end result runs in a devastating way such as fracture, head trauma, cerebral contusion and other injuries. The financial cost of fall among the PD patients is very high and it demands twice or more for the direct medical cost of PD faller than no fallers groups. [8] Besides the conventional risk factors of fall among the idiopathic Parkinson's patients, the other comorbidities that may precipitate and play a vital role responsible for fall and fall related events. The major comorbid conditions (e. g. obesity, hypertension, and diabetes mellitus) may potentiate many diseases as their prevalence is growing rapid now a day worldwide. So, fall and its consequences would be a major public health burden in near future, with the view of this knowledge, we have designed this study in a small scale to assess the frequency of risk factor associated with fall among the idiopathic PD patients in the district of Jashore, Bangladesh. It will help in early detection of risk factors associated and reduce the risk fall with appropriate early intervention.

\section{Methodology}

\subsection{Study Design and Settings}

This observational study was conducted from July to December, 2018 in a teaching hospital named Jashore Medical College \& Hospital, Bangladesh. The study recruited 111 cases of newly attended idiopathic Parkinson's patients of both sexes. Those having Parkinson's disease due to stroke or secondary causes, orthostatic hypotension, taking anti parkinsonian drugs and the drugs may mimic Parkinson's disease were excluded from this study. Furthermore, idiopathic Parkinson's patients who are completely bed ridden and underwent functional stereotactic surgery for Parkinson's disease were excluded from the study. The diagnosis of PD was confirmed according to the United Kingdom Parkinson's Disease Brain Bank criteria. [9] All the subjects were enrolled after taking a written informed voluntary consent. Institutional approval was taken from Superintendent of Jashore Medical College Hospital, Bangladesh. After getting the informed written consent, a detailed history and physical examinations were carried out among the index participants. A structured questionnaire was used to collect information from every patient regarding age, sex, residence, education, occupation (current or previous), history of hypertension \& diabetes, duration of disease, number of medications taking regularly and lastly the number of falls experienced within the past one year. Here fall considered only occurred spontaneously without any precipitating factors and three or more fall within this period considered as frequent fall. Standing height was measured to the nearest millimeter by using a stadiometer. Participants were weighed in light clothing without footwear. Body weight was measured to the nearest $0.1 \mathrm{~kg}$ by using an Electronic Weighing Scale (Sinbe Model No, SBS 4414 and made in People's Republic of China). We used the classifications of BMI (weight in $\mathrm{kg} /$ height in $\mathrm{m}^{2}$ ) recommended by the WHO. [10].

\subsection{Case Definition of Fall}

A fall was denoted as an event that occurred in the patient unintentionally bring him to the ground or other lower level not as a result of a major intrinsic event or overwhelming hazards. $[1,11]$ The patients were asked about the number of falls in the previous one year. It was crossed checked by the attending relatives, family members or care giver for accuracy of the data.

\subsection{Statistical Analysis}

Continuous data presented as mean and standard deviation and categorical data presented in percentages. Independent sample t-test and chi-square test employed to extract $\mathrm{p}$-value. SPSS version 22 was used for statistical analysis.

\section{Results}

We had divided all the patients into non faller and faller groups. The event of fall among the idiopathic Parkinson's patients constituted $36.9 \%$ within the last one year. [Table-1].

Table 1. Frequency of fall in last one year of Parkinsonism Patients. (n:111).

\begin{tabular}{llll}
\hline Study subjects & & $\mathbf{n}$ & $\mathbf{\%}$ \\
\hline No fall & & 70 & 63.1 \\
& Single episode of fall & 23 & 20.7 \\
Fall & Two episodes of fall & 4 & 3.6 \\
& Three or more episodes of fall & 14 & 12.6 \\
Total & & 111 & 100.0 \\
\hline
\end{tabular}

$\mathrm{n}=$ Number, $\%=$ percentage.

Out of 111 patient's males were $77(69.4 \%)$ and female were $34(30.6 \%)$ (Male: Female $=2.27)$ with mean age $66 \pm 10$ years. According to the educational qualification the maximum patients were of secondary educational level 
(48.7\%) followed by no education (23.4\%), primary (14.4\%) and graduation level (13.5\%) in our study. [Table 2]

Table 2. Demographic characteristics of study subjects with relation to fall. (n:111).

\begin{tabular}{|c|c|c|c|c|}
\hline Demographic Characteristics & All patients $(n=111,100 \%)$ & Non-faller $(n=70,63.1 \%)$ & Faller $(n=41,36.9 \%)$ & P-value \\
\hline \multicolumn{5}{|l|}{ Age in years: } \\
\hline Mean \pm SD & $66 \pm 10$ & $65 \pm 11$ & $68 \pm 8$ & $0.091^{\mathrm{ns}}$ \\
\hline Min- Max & $35-91$ & $35-91$ & $50-90$ & \\
\hline \multicolumn{5}{|l|}{ Sex: $(M: F=2.27)$} \\
\hline Male n (\%) & $77(69.4)$ & $53(47.7)$ & 24 (21.6) & $0.058^{\mathrm{ns}}$ \\
\hline Female n (\%) & $34(30.6)$ & $17(15.3)$ & $17(15.3)$ & \\
\hline Education: & & & & $0.235^{\mathrm{ns}}$ \\
\hline No education $\mathrm{n}(\%)$ & $26(23.4)$ & $13(11.7)$ & $13(11.7)$ & \\
\hline Primary n (\%) & $16(14.4)$ & $13(11.7)$ & $03(02.7)$ & \\
\hline Secondary n (\%) & 54 (48.7) & $34(30.6)$ & $20(18.0)$ & \\
\hline Graduation n (\%) & $15(13.5)$ & $10(09.1)$ & $05(04.5)$ & \\
\hline \multicolumn{5}{|l|}{ Occupation: } \\
\hline Housewife n (\%) & 34 (30.6) & $19(17.1)$ & $15(13.5)$ & \\
\hline Farmer n (\%) & $18(16.2)$ & $15(13.5)$ & $03(02.7)$ & $0.220^{\mathrm{ns}}$ \\
\hline Service n (\%) & $33(29.8)$ & $19(17.1)$ & $14(12.6)$ & \\
\hline Business n (\%) & $26(23.4)$ & $17(15.3)$ & $09(08.1)$ & \\
\hline \multicolumn{5}{|l|}{ Residency: } \\
\hline Urban n (\%) & $42(37.8)$ & $25(22.5)$ & $17(15.3)$ & $0.547^{\mathrm{ns}}$ \\
\hline Rural n (\%) & $69(62.2)$ & $45(40.6)$ & $24(21.6)$ & \\
\hline
\end{tabular}

$\mathrm{SD}=$ Standard deviation, Min= Minimum, Max $=$ Maximum, $\mathrm{n}=$ Number and $\mathrm{ns}=$ Not significant. $\mathrm{P}$-value extracted from independent sample $\mathrm{t}$-test and chisquare test.

Total study participants were subdivided according to occupation in housewife, farmer, service and business which constituted $34(30.6 \%), 18(16.2 \%) 33(29.8 \%)$ and 26 $(23.4 \%)$ but the maximum cohorts of the faller were came from the house wife group which constituted $13.5 \%$. In the present study $69(62.2 \%)$ participants were from the rural society and the rest $42(37.8 \%)$ from the urban area. No significant difference observed between faller and non-fallers among different demographic characteristics including age ( $p: 0.091)$ sex ( $p: 0.058)$ educational level ( $p: 0.235)$, occupational status $(p: 0.220)$ and residency $(p: 0.547)$. [Table-2]

The mean duration of disease in year among the all participants, non-faller and faller group were $4.25 \pm 4.96$, $4.33 \pm 5.09$ and $4.12 \pm 4.79$ respectively, and the result was insignificant $(p-0.835)$. The mean BMI among the faller group was $24.48 \pm 4.79 \mathrm{~kg} / \mathrm{m}^{2}$ and in case of non-faller group $22.93 \pm 3.75 \mathrm{~kg} / \mathrm{m}^{2}$ and we had found a significant relationship between obesity (higher BMI) and fall in our study ( $p-0.037)$. Out of total participants $69.4 \%(n-77)$ were hypertensive and the rest $30.6 \%(n-34)$ were normotensive, here hypertensive patients significantly more in the faller group ( $p-0.018)$. Diabetes played as a risk factor for potentiating fall in the present study $(p-0.009)$. It was postulated that fall accounted more common in patients taking more number of medication and less common in patients treated with single or no medication $(p-0.011)$. So, number of faller found more in high BMI, hypertensive, diabetic patients and in patients receiving multiple medications, but duration of Parkinsonism did not increase fall. [Table-3]

Table 3. Risk factor association of faller in Parkinsonism (n: 111).

\begin{tabular}{|c|c|c|c|c|}
\hline Risk factors & All patients $(n=111,100 \%)$ & Non-faller $(n=70,63.1 \%)$ & Faller $(n=41,36.9 \%)$ & P-value \\
\hline \multicolumn{5}{|c|}{ Duration of Parkinsonism in years } \\
\hline Mean \pm SD & $4.25 \pm 4.96$ & $4.33 \pm 5.09$ & $4.12 \pm 4.79$ & \multirow[t]{2}{*}{$0.835^{\mathrm{ns}}$} \\
\hline Min- Max & $1-25$ & $1-25$ & $50-90$ & \\
\hline \multicolumn{5}{|l|}{$B M I$ in $\mathrm{kg} / \mathrm{m}^{2}$ : } \\
\hline Mean \pm SD & $23.50 \pm 3.80$ & $22.93 \pm 3.75$ & $24.48 \pm 4.79$ & \multirow[t]{2}{*}{$0.037^{\mathrm{s}}$} \\
\hline Min- Max & $16.2-32.5$ & $16.2-32.5$ & $18.6-31.8$ & \\
\hline \multicolumn{5}{|l|}{ Hypertension: } \\
\hline Hypertensive; n (\%) & $77(69.4)$ & $43(38.7)$ & $34(30.6)$ & \multirow[t]{2}{*}{$0.018^{\mathrm{s}}$} \\
\hline Non- hypertensive; n (\%) & $34(30.6)$ & $27(24.4)$ & $07(06.3)$ & \\
\hline \multicolumn{5}{|l|}{ Diabetes Mellitus: } \\
\hline Diabetic; n (\%) & $30(27.0)$ & $13(11.7)$ & $17(15.3)$ & \multirow[t]{2}{*}{$0.009^{\mathrm{s}}$} \\
\hline Non-diabetic; n (\%) & $81(73.0)$ & $57(51.4)$ & $24(21.6)$ & \\
\hline \multicolumn{5}{|l|}{ Number of Medications: } \\
\hline No medication; n (\%) & $23(20.7)$ & $18(16.2)$ & $05(04.5)$ & \multirow{5}{*}{$0.011^{\mathrm{s}}$} \\
\hline Single; n (\%) & $23(20.7)$ & $18(16.2)$ & $05(04.5)$ & \\
\hline Two; n (\%) & $25(22.6)$ & $13(11.7)$ & $12(10.8)$ & \\
\hline Three; n (\%) & $20(18.0)$ & $14(12.6)$ & $06(05.4)$ & \\
\hline Four or more; $\mathrm{n}(\%)$ & $20(18.0)$ & $07(06.3)$ & $13(11.7)$ & \\
\hline
\end{tabular}

$\mathrm{SD}=$ Standard deviation, Min $=$ Minimum, Max $=$ Maximum, $\mathrm{n}=$ Number, $\mathrm{ns}=$ Not significant and $\mathrm{s}=$ Significant.

$\mathrm{P}$-value extracted from independent sample t-test and chi-square test. 


\section{Discussion}

This was a hospital based study, not a community-based epidemiological survey. The rate of fall among the present study groups was $36.9 \%$ within the last one year whereas one study reported that $45 \%$ have experienced of fall within $2-4$ years since diagnosis which is near similar to our study. [12].

Fall among the Parkinson's patients is related to the age of patient, disease duration and severity, dyskinesia associated with the use of dopaminergic agents, freezing, postural instability, depression, impaired fine motor control and motor planning in the feet, decreased proximal muscle strength and muscular endurance in the legs, joint deformity, visual impairment and used medications. In our study we have assessed the relationship of fall among the idiopathic Parkinson's patients with some socio-demographic characteristics and comorbidity conditions e.g., duration of disease, obesity, hypertension, diabetes and number of daily medications.

Increasing age is associated with increasing frequency of fall but we have not found that increased age is related to fall in our study. [12] Similarly other demographic factors such as gender, education, occupation and residency are not associated with fall among the Parkinson's patients in our present study.

Diabetes is one of the growing public health issues worldwide and it is associated with neurodegenerative diseases. Large prospective studies have shown that type 2 diabetes is associated with increased risk of Parkinson's disease among the Finish men and women. [13] A systemic review and meta-analysis have reported that diabetes appears to be a risk factor for PD. [14] Abnormal glucose metabolism enhances the motor severity and cognitive impairment and postural impairment of the Parkinson's patients which may be a potentiating factor of fall among them. [15] In our study we have found that fall is more among the diabetic Parkinson's patients.

Regular use of medication is a common scenario in aged people. In our study we have considered only those medication which our patients using regularly e.g., antihypertensive, antidiabetic, sedatives, hypnotics, antidepressant and antipsychotics. Especially antidepressant and antipsychotic medications due to their sedative effects are related to fall. [16] Even polypharmacy has reported to be a significant risk factor of developing Parkinson's disease. [17] The present study has shown that fall is more in patients taking more medication and fall is less common in patients taking single or no medication.

Blood pressure abnormality is one of the most common autonomic dysfunctions among the PD patients such as orthostatic hypotension, postprandial hypotension and nocturnal hypertension. [18-20] In our study we have excluded PD patients with having orthostatic hypotension though it is an independent risk factor of fall among the PD patients. The Parkinson's patients with orthostatic hypotension experience of fall frequently than control group.
Even though PD patients with hypertension have experienced more fall in our study.

The obese Parkinson's patients having high BMI are more prone to develop osteoporosis which in turn to be a risk factor of fall in PD patients. One study has reported similar finding that more BMI has more risk of fall among the PD patients in our study. [21].

Increase duration of disease is associated with increased risk of fall among the PD patients, a well-recognized fact but the present study has failed to show this association. [22] This is possibly due to inadequate number of patients included in our study and sampling method.

\section{Limitation of the Study}

The present study is limited to the patients only. Extensive evaluation of the patients was not done in the study. We did not to do staging and severity of the patients.

\section{Conclusion}

Frequency of fall among idiopathic Parkinson's disease is high. Risk factors like obesity, hypertension, diabetes and polypharmacy are associated with fall. Earlier detection of crucial risk factors and potential intervention to remove the risk factors may play the vital role to prevent falls and related events, thus finally reducing the morbidity and mortality in the Parkinson's patients.

\section{Authors' Disclosures of Potential Conflicts of Interest}

All the authors do not have any possible conflicts of interest.

\section{References}

[1] Tinetti ME, Williams CS. Falls, Injuries Due to Falls, and the Risk of Admission to a Nursing Home. The New England Journal of Medicine. 1997; 337: 1279-1284.

[2] Thurman DJ, Stevens JA, Rao JK. Practice Parameter: Assessing patients in a neurology practice for risk of falls: Report of the Quality Standards Subcommittee of the American Academy of Neurology. Neurology. 2008; 70: 473479.

[3] Farombi TH, Owolabi MO, Ogunniyi A. Falls and Their Associated Risks in Parkinson's disease Patients in Nigeria. Journal of Movement Disorders. 2016; 9 (3): 160-165.

[4] Allen NE, Schwarzel AK, Canning CG. Recurrent falls in Parkinson's disease: a systematic review. Parkinsons Dis. 2013; 2013: 906274.

[5] Torsney KM, Noyce AJ, Doherty KM, Bestwick JP, Dobson $\mathrm{R}$, Lees AJ. Bone health in Parkinson's disease: a systematic review and meta-analysis. J Neurol Neurosurg Psychiatry. 2014; 85: 1159-1166. 
[6] van der Marck MA, Klok MP, Okun MS, Giladi N, Munneke M, Bloem BR, Falls Task Force NPF. Consensus-based clinical practice recommendations for the examination and management of falls in patients with Parkinson's disease. Parkinsonism Relat Disord. 2014; 20 (4): 360-369.

[7] Huang Y-F, Cherng Y-G, Hsu SPC, et al. Risk and adverse outcomes of fractures in patients with Parkinson's disease: two nationwide studies. Osteoporos Int. 2015; 26: 1723-1732.

[8] Melton LJ, III, Leibson CL, Achenbach SJ, et al. Fracture risk after the diagnosis of Parkinson's disease: influence of concomitant dementia. Movement Disorders. 2006; 21 (9): 1361-1367.

[9] Hughes AJ, Ben-Shlomo Y, Daniel SE, Lees AJ. What features improve the accuracy of clinical diagnosis in Parkinson's disease: a clinicopathologic study. Neurology. 1992; 42 (6): 1142-1146.

[10] World Health Organization. The Asia-Pacific perspective: redefining obesity and its treatment.

[11] Tinetti ME, Speechley M, Ginter SF. Risk factors for falls among elderly persons living in the community. The New England Journal of Medicine. 1988; 319 (26): 1701-1707.

[12] Voss TS, Elm JJ, Wielinski CL, et al. Fall Frequency and Risk Assessment in Early Parkinson's Disease. Parkinsonism \& related disorders. 2012; 18 (7): 837-841.

[13] Hu G, Jousilathi P, Bidel S, Antikainen R, Toumilehto J. Type 2 Diabetes and the Risk of Parkinson's Disease. Diabetes Care. 2007; 30 (4): 842- 847.

[14] Cereda E, Barichelle M, Pedrolli C, et al. Diabetes and Risk of Parkinson's Disease. Diabetes Care. 2011; 34(12): 2614-2623.
[15] Sandyk R, Awerbuch GI. The association of Diabetes Mellitus with Dementia in Parkinson's disease. International Journal of Neuroscience. 1992; 64: 1-4, 209-212.

[16] Parashos SA, Wielinski CL, Giladi N, Gurevich T. National Parkinsons Foundation Quality Improvement Initiative Investigators. Falls in Parkinson disease: analysis of a large cross-sectional cohort. J Parkinsons Dis. 2013; 3: 515-522.

[17] Lai sw, Su LT, Lin CH, Tsai CH, Sung FC, Hsieh PH. Polypharmacy increases the risk of Parkinson's disease in older people in Taiwan: A population-based study. Phychogeriatrics. 2011; 11: 150-156.

[18] Ejaz AA, Sekhon IS, Munjal S. Characteristic findings on 24$\mathrm{h}$ ambulatory blood pressure monitoring in a series of patients with Parkinson's disease. Eur. J. Inter. Med. 2006; 17: 417420 .

[19] Gross M, Bannister R, Godwin-Austen R. Orthostatic hypotension in Parkinson's disease. Lancet. 1972; 1: 174-176.

[20] Sharabi Y, Goldstein DS. Mechanisms of orthostatic hypotension and supine hypertension in Parkinson disease. J. Neurol. Sci. 2011; 310: 123-128.

[21] Bezza A, Ouzzif Z, Naji H, et al. Prevalence and risk factors of osteoporosis in patients with Parkinson's disease. Rheumatol Int. 2008; 28: 1205-1209.

[22] Balash Y, Peretz C, Leibovich G, Herman T, Hausdorff JM, Giladi N. Falls in outpatients with Parkinson's disease: frequency, impact and identifying factors. J Neurol. 2005; 252: $1310-1315$. 